\title{
Organophosphate esters in dust samples collected from Danish homes and daycare centers
}

\author{
Langer, Sarka; Fredricsson, Malin; Weschler, Charles J.; Bekö, Gabriel; Strandberg, Bo; Remberger, \\ Mikael; Toftum, Jørn; Clausen, Geo
}

\section{Published in:}

Chemosphere

Link to article, DOI:

10.1016/j.chemosphere.2016.04.016

Publication date:

2016

Document Version

Peer reviewed version

Link back to DTU Orbit

Citation (APA):

Langer, S., Fredricsson, M., Weschler, C. J., Bekö, G., Strandberg, B., Remberger, M., Toftum, J., \& Clausen, G. (2016). Organophosphate esters in dust samples collected from Danish homes and daycare centers. Chemosphere, 154, 559-566. https://doi.org/10.1016/j.chemosphere.2016.04.016

\section{General rights}

Copyright and moral rights for the publications made accessible in the public portal are retained by the authors and/or other copyright owners and it is a condition of accessing publications that users recognise and abide by the legal requirements associated with these rights.

- Users may download and print one copy of any publication from the public portal for the purpose of private study or research.

- You may not further distribute the material or use it for any profit-making activity or commercial gain

- You may freely distribute the URL identifying the publication in the public portal 


\section{Organophosphate esters in dust samples collected from Danish homes and daycare centers}

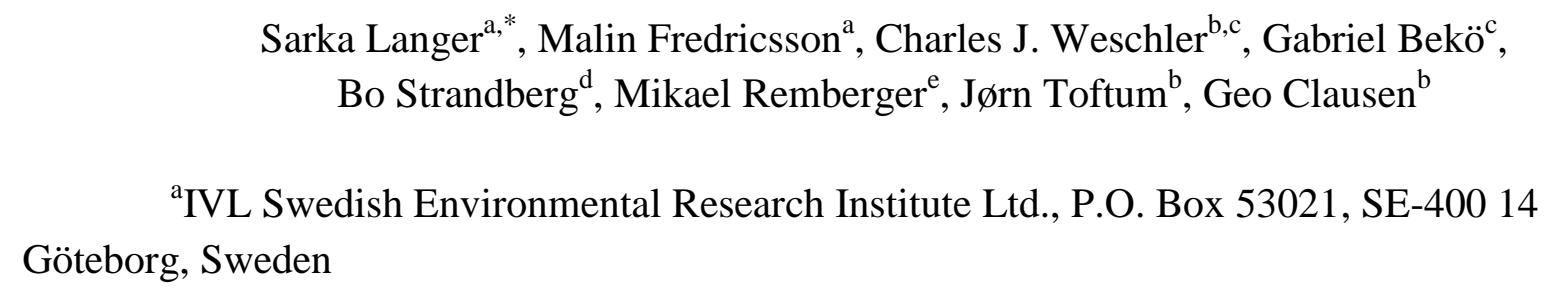

${ }^{a}$ IVL Swedish Environmental Research Institute Ltd., P.O. Box 53021, SE-400 14

Göteborg, Sweden

${ }^{\mathrm{b}}$ International Centre for Indoor Environment and Energy, Department of Civil Engineering, Technical University of Denmark, DK-2800 Lyngby, Denmark

${ }^{c}$ Environmental and Occupational Health Sciences Institute, Rutgers University, Piscataway, New Jersey, 08854, United States

${ }^{\mathrm{d}}$ Occupational and Environmental Medicine, Sahlgrenska Academy at University of Gothenburg, Box 414, SE-405 30, Göteborg, Sweden

${ }^{\mathrm{e}}$ IVL Swedish Environmental Research Institute Ltd., P.O. Box 210 60, SE-100 31

Stockholm, Sweden

*Corresponding author:

sarka.langer@ivl.se; IVL Swedish Environmental Research Institute Ltd., P.O. Box 53021, SE-400 14 Göteborg, Sweden; phone: +46 (0)10 7886897

Keywords: exposure, flame retardants, indoor environment, plasticizers, SVOC

Highlights

- Organophosphates were determined in dust from 497 homes and 151 daycare centers

- Mass fractions in dust from daycare centers were larger than in dust from homes

- Estimated exposures to organophosphates via dust ingestion were relatively low

- The country-to-country distribution of organophosphates is more variable than that of phthalate esters 


\section{Abstract}

Organophosphates are used in a wide range of materials and consumer products and are ubiquitous in indoor environments. Certain organophosphates have been associated with various adverse health effects. The present paper reports mass fractions of organophosphates in dust samples collected from 500 bedrooms and 151 daycare centers of children living in Odense, Denmark. The identified compounds include: tris(isobutyl) phosphate (TIBP), tri-nbutyl phosphate (TNBP), tris(2-chloroethyl) phosphate (TCEP), tris(2-chloroisopropyl) phosphate (TCIPP), tris(1,3-dichloroisopropyl) phosphate (TDCIPP), tris(2-butoxyethyl) phosphate (TBOEP), triphenylphosphate (TPHP), 2-ethylhexyl-diphenyl phosphate (EHDPP), tris(2-ethylhexyl) phosphate (TEHP) and tris(methylphenyl) phosphate (TMPP). Both the number of organophosphates with median values above the limit of detection and the median values were higher for samples from daycare centers than for samples from homes.

Organophosphates with median mass fractions above the limit of detection were: TCEP from homes $\left(6.9 \mu \mathrm{g} \mathrm{g}^{-1}\right)$, and TCEP $\left(16 \mu \mathrm{g} \mathrm{g}^{-1}\right)$, TCIPP $\left(5.6 \mu \mathrm{g} \mathrm{g}^{-1}\right)$, TDCIPP $\left(7.1 \mu \mathrm{g} \mathrm{g}^{-1}\right)$, TBOEP $\left(26 \mu \mathrm{g} \mathrm{g}^{-1}\right)$, TPHP $\left(2.0 \mu \mathrm{g} \mathrm{g}^{-1}\right)$ and $\operatorname{EHDPP}\left(2.1 \mu \mathrm{g} \mathrm{g}^{-1}\right)$ from daycare centers. When present, TBOEP was typically the most abundant of the identified OPs. The sum of the organophosphate dust mass fractions measured in this study was roughly in the mid-range of summed mass fractions reported for dust samples collected in other countries. On a global scale, the geographical distribution of organophosphates in indoor dust is quite variable, with higher concentrations in industrialized countries. This trend differs from that for phthalate esters, whose geographic distribution is more homogeneous. Exposure to organophosphates via dust ingestion is relatively low, although there is considerable uncertainly in this assessment.

\section{Introduction}


Semivolatile organic compounds (SVOC) are ubiquitous in indoor environments, and, depending on their chemical properties, can persist for a very long time (Weschler and Nazaroff, 2008; Shin et al., 2013). Indoor SVOCs commonly include organophosphate triesters. The use of the organophosphates is increasing because of their favorable properties as both flame retardants and plasticizers (Marklund et al., 2003). The halogenated organophosphates are mostly used as flame retardants while the non-halogenated compounds are generally used as plasticizers (Andresen et al., 2004). Organophosphorus flame retardants are found in a wide range of commercial products including textiles, rubber, polyurethane foam (PUF), antistatic formulations, cellulose, cotton, cutting oils, electronic equipment, glues, engineering thermoplastics, epoxy resins and phenolic resins (Marklund et al., 2005). Polyvinyl chloride (PVC) is an example of a product where phosphorus flame retardants also function as plasticizers (Marklund et al., 2003).

Organophosphates have been implicated in various adverse health effects, including skin irritation and contact dermatitis in humans, and neurological and carcinogenic effects in rats (WHO 1991 a,b, 1998, 2000). Araki et al. (2014) have recently found associations between organophosphates flame retardants and atopic dermatitis, asthma and allergic rhinitis. Organophosphates have also been associated with altered hormone levels and decreased semen quality in men (Meeker and Stapleton, 2010).

The widespread use of organophosphates in everyday products results in redistribution from their original source into other indoor compartments, including indoor air, airborne particles, settled dust and all exposed indoor surfaces (e.g. Marklund et al., 2005; Wensing et al., 2005). They were first reported in indoor airborne particles in 1980 (Weschler, 1980). Their concentrations have been found to be much higher indoors than outdoors, reflecting the much greater presence of their sources indoors compared to outdoors (Weschler et al., 1984: Staaf and Östman, 2005; Wensing et al., 2005). The mass fractions of various 
organophosphates in settled dust have been determined over the past 14 years in samples collected from homes, daycare centers and workplaces in various countries throughout the world (Brommer and Harrad, 2015; He et al., 2015; Hoffman et al., 2015; Luongo annd Östman, 2015; Abdallah and Covaci, 2014; Araki et al., 2014; Cequier et al., 2014; Fan et al., 2014; Fromme et al., 2014; Shin et al., 2014; Tajima et al., 2014; Ali et al., 2013; Brommer et al., 2012; Kim et al., 2013; Dodson et al., 2012; Ali et al., 2012a; Ali et al., 2012b, Bergh et al., 2011, Van den Eede et al., 2011; Dirtu et al., 2010; Kazanawa et al., 2010; Meeker and Stapleton, 2010; Stapleton et al., 2009; García et al., 2007; Wensing et al., 2005; Marklund et al., 2003; Nagorka and Ullrich, 2003, Kersten and Reich, 2003; Becker et al., 2002; Ingerowski et al., 2001). Human exposure to organophosphates is apparent from biomonitoring studies, which have detected various organophosphate metabolites in urine samples (e.g., Reemtsma et al., 2011; Fromme et al., 2014; Hoffman et al., 2014). A recent study found that levels of such metabolites in urine correlated with levels of organophosphates in dust, and that children's exposure to organophosphates can be related to levels found in their indoor environments (Cequier et al., 2015).

The aim of the present paper is threefold: to report the mass fractions of selected organophosphate esters (OPEs) measured in the dust samples collected from children's bedrooms $(n=500)$ and daycare centers $(n=151)$ as part of the IECH investigation; to examine potential correlations between levels of the individual organophosphates, both in the children's bedrooms and daycare facilities; and to compare the results with those reported in other studies to derive a sense of variations over geographic location and time. The information presented in this paper can be used to improve understanding of Danish children's exposure to organophosphate esters. 


\section{Material and Methods}

108

109

110

111

112

113

114

115

116

117

\subsection{Study design}

The Danish study “Indoor Environment and Children's Health (IECH)” has investigated the relationship between children's health and their indoor environments. The design of the IECH study and the methods used in the investigations have been described by Clausen et al. (2012). Questionnaires were sent to 17,486 families that had children between the ages of one and five. All children in the study lived on the Danish island of Fyn $(482,310$ inhabitants). The final database contained questionnaires from 11,082 children, i.e. the response rate was $63 \%$. Using the information from the survey, 500 children between the ages of three and five and living in Odense (166,000 inhabitants) were selected for the case-base study: 200 "cases" with asthma/allergies and 300 randomly selected "bases", i.e. both healthy and sick children. All of the daycare facilities attended by these children were also included in the study $(\mathrm{n}=151)$. Settled dust was collected from the children's bedrooms from non-floor surfaces such as shelves, ledges, and window sills as well as from horizontal non-floor surfaces in the daycare centers. Dust from floors was avoided, since it may be contaminated by direct contact with organophosphorus flame retardants or plasticizers present at the surfaces of flooring materials that contain these additives. The dust samples were subsequently analyzed for five phthalate esters and three polycyclic aromatic hydrocarbons (Langer et al., 2010) as well as for squalene and cholesterol (Weschler et al., 2011).

\subsection{Dust collection}

Dust was collected from non-floor surfaces in the children's bedrooms and daycares using ALK dust filters (ALK-Abelló A/S, Hørsholm, Denmark) mounted in a holder connected to a vacuum cleaner. Collection of dust from plastic surfaces and textiles was 
avoided. In 5\% of the homes (randomly chosen) a field blank was obtained (filter was mounted in the holder but no sampling was performed).

\subsection{Chemical analysis}

Prior to sampling, the virgin filters were pre-conditioned at a temperature of $23 \pm 1$ ${ }^{\circ} \mathrm{C}$ and relative humidity of $50 \pm 5 \%$, weighed and assigned an ID number. The loaded filters or blanks were returned to the laboratory (shipped at ambient temperature) where they were conditioned, weighed, wrapped in aluminum foil and re-packed in their original bag. The net dust mass on the loaded filters ranged from 43 to $1396 \mathrm{mg}$ (average $198 \mathrm{mg}$; median $160 \mathrm{mg}$ ). Of the total number of more than 700 filters that were analyzed, $33(\sim 5 \%)$ were field blanks, and 42 were laboratory blanks.

The organic compounds in the dust were extracted using the procedure described by Rudel et al. (2003). Logistics and details of the chemical analysis are presented in the Supplementary Material.

The organophosphate esters evaluated in this study, in order of retention times, were: tris(isobutyl) phosphate (TIBP), tri-n-butyl phosphate (TNBP), tris(2-chloroethyl) phosphate (TCEP), tris(2-chloroisopropyl) phosphate (TCIPP), tris(1,3-dichloroisopropyl) (TDCIPP), tris(2-butoxyethyl) phosphate (TBOEP), tri-phenylphosphate (TPHP), 2-ethylhexyl-diphenyl phosphate (EHDPP), tris(2-ethylhexyl) phosphate (TEHP) and tris(methylphenyl) phosphate (TMPP). The compounds were named and abbreviated according to the nomenclature proposed by Bergman et al. (2012).

The original target compounds in these dust samples were phthalate esters and polycyclic aromatic hydrocarbons (Langer et al., 2010). After the samples were extracted and analyzed, we recognized peaks in the Total Ion Chromatograms (TIC) that corresponded to organophosphate esters. As the organophosphates were not targeted from the beginning, their 
recoveries could not be determined using appropriate isotopically labelled standards. Given that phthalate esters and organophosphate esters span similar ranges of physical and chemical properties (Wensing et al., 2005), we assume that the efficiency with which they are extracted from the dust, using 6\% diethyl ether in hexane for $16 \mathrm{~h}$, is similar (Toda et al., 2004). To support this, we have determined the recoveries of a phthalate $\left(\mathrm{d}_{4}\right.$-di-isononyl phthalate (DnOP-d 4 ); c.f. Langer et al., 2010) and a phosphate (triamylphosphate (TAP); c.f. Brommer et al., 2012) from dust samples collected onboard the Swedish icebreaker Oden. Seven dust samples were extracted and analyzed by the same procedure as the samples from this study. The recoveries were similar: $0.96 \pm 0.09$ and $0.99 \pm 0.09$ for TAP and DnOP- $\mathrm{d}_{4}$, respectively. Furthermore, using methods similar to those used in the present study, good procedural recoveries of 90-110\% for the organophosphates have been reported in the literature (e.g., Van den Eede et al., 2011).

The organophosphate esters were first identified by their mass spectra in the TICs and matched against their mass spectra in the NIST (National Institute of Standards and Technology) Mass Spectral Library. They were later also matched against the mass spectra of the authentic compounds used to prepare the calibration standards. The 10 target compounds were then quantified with the "Extraction Ion" procedure from the full scan chromatograms using the m/z-ratio (mass-to-charge) for the most abundant ion in each compound (Table 1); $\mathrm{m} / \mathrm{z}=266$ was selected for 1,2,3,4-tetrachloronaphthalene. For the purpose of quantification, a five-point standard curve for each of the ten organophosphates was prepared, in the range of $0.1-5.0 \mathrm{ng} \mu \mathrm{L}^{-1}$ with $2.0 \mathrm{ng} \mu \mathrm{L}^{-1}$ of 1,2,3,4-tetrachloronaphthalene as the injection standard, also using the $\mathrm{m} / \mathrm{z}$ ratio for the most abundant ions (Table 1). The limits of detection (LOD) were calculated from the standard deviations of the repeated injections of the analytical standards plotted against their concentrations (Taylor, 1987). The value of the standard deviation as the concentration approaches zero $\left(\mathrm{S}_{0}\right)$ was determined as the intercept of the 
best-fit straight line of this plot. Limits of detection were then calculated as $3 \times \mathrm{S}_{0}$. These limits of detection are on the high end of those reported in the literature (see studies summarized in Table 4). The magnitude of the detection limits using GC/MS is partially a consequence of the operating mode of the mass spectrometer. Selected Ion Monitoring (SIM) is more sensitive (lower amounts detected) than using extracted ions from the TICs. Nonetheless, some studies report comparable limits of detection (e.g. Tajima et al. (2014). The organophosphates in the blanks were all below the limits of detection, with the exception of TIBP $(0.06 \pm 0.05 \mu \mathrm{g} /$ filter $)$. After correcting for the amount of TIBP found in the blank samples, the values of all the other organophosphates below the LOD were replaced with a value one-half the LOD. The amounts of the organophosphates in the dust samples were expressed as their mass fractions in units of $\mu \mathrm{g}$ of the compound per gram of dust ( $\mu \mathrm{g} \mathrm{g}^{-}$ $1)$.

\section{Results and Discussion}

Reliable measurements were obtained for dust samples from 497 homes (1 sample lost, 2 with analytical issues) and from all 151 daycare centers. Not all the targeted compounds were found in all samples. Only TCEP, TCIPP and TDCIPP were identified in more than a third of the home samples, while only TCEP, TCIPP, TDCIPP, TBOEP, TPHP and EHDPP were identified in more than a third of the daycare samples. Descriptive statistics of the results are presented in Table 2 for both the homes and daycare centers. For each organophosphate the table lists detection frequency (DF; i.e., the percentage of samples with values above the LOD), LOD, and the median, $90^{\text {th }}$ percentile, and maximum mass fractions.

\subsection{The organophosphates in dust from homes and daycare centers}


Figure $1(\mathrm{a}-\mathrm{c})$ presents plots of the natural logarithm of selected organophosphate

mass fractions in homes and daycare centers against the cumulative distribution function, with the $\mathrm{x}$-axis scaled according to the normal error function. The figures show only the organophosphates evaluated in this study that had median values above $1 / 2$ the LOD. For each compound, in both homes and daycare centers, the plots are roughly linear, indicating that the distribution of the concentrations is better described as "log-normal" than "normal". This is consistent with expectations (Ott, 1995) and earlier studies of indoor volatile organic compounds (e.g. Shields et al., 1996).

Table 3 presents Spearman correlation coefficients for the individual organophosphates. While there are many statistically significant correlations, there are only a few compounds that are strongly correlated. These are TCEP/TIBP in homes and TDCIPP/TCIPP and EHDPP/TPHP in daycare centers. The mass fractions of all organophosphates except TIBP, TEHP and TMPP were significantly different between homes and daycare centers ( $\mathrm{p}<0.05$; non-parametric two-sample Wilcoxon rank-sum (Mann Whitney) test, as the data were not normally distributed; STATA software, release 11.2 for Windows, StataCorp LP, College Station, Texas, USA).

TCEP was found in $\geq 50 \%$ of the dust samples from both the children's homes and daycare centers. The median mass fraction of TCEP from the daycare centers $\left(16 \mu \mathrm{g} \mathrm{g}^{-1}\right)$ was more than twice as high as the concentration from homes $\left(6.9 \mu \mathrm{g} \mathrm{g}^{-1}\right)$. The median mass fractions of TCIPP and TDCIPP were noticeably different for the daycare center dust (5.6 $\mu \mathrm{g}$ $\mathrm{g}^{-1}$ and $7.1 \mu \mathrm{gg}^{-1}$, respectively) and the home dust $\left(0.5 \mu \mathrm{g} \mathrm{g}^{-1}\right.$ and $0.6 \mu \mathrm{g} \mathrm{g}^{-1}$, respectively; both $=1 / 2 \mathrm{LOD})$. centers than in the homes. TCEP and TCIPP, which are chlorinated organophosphorus flame 
retardants, are mostly used in flexible foams such as polyurethane foam (PUF) that can be found in products such as cushions, upholstered furniture, pillows and mattresses (WHO, 1998). Bergh et al. (2011) also found TCEP and TCIPP to have higher concentrations in daycare centers compared to homes, with TCEP being the second most common organophosphate in the daycare centers. In the study by Marklund et al. (2003), TCEP and TCIPP had relatively low concentrations in the homes as well as the one daycare center they sampled, but the concentration was still higher in the daycare center compared with the homes. Concentrations of chlorinated OPEs in dust from homes in general seem to be lower compared to other public places such as work environments (Bergh et al., 2011). Marklund et al. (2003) found higher levels of TDCIPP $\left(1.8 \mu \mathrm{g} \mathrm{g}^{-1}\right)$ in a daycare center compared to the average value for two homes $\left(0.75 \mu \mathrm{g} \mathrm{g}^{-1}\right)$; the number of samples in that study is, however, very limited. The findings of Bergh et al. (2011) differ from the results of this study: they detected similar levels in the homes and daycare centers $\left(10 \mu \mathrm{g} \mathrm{g}^{-1} v s .9 .1 \mu \mathrm{g} \mathrm{g}^{-1}\right)$. Fromme et al. (2014) report TCEP and TCIPP from German daycare centers with TCIPP being the second most abundant organophosphate in their study. In the present study it should be noted that even though TDCIPP was detected in a smaller percentage of samples from homes (DF = $41 \%)$ than in samples from daycare centers $(\mathrm{DF}=67 \%)$, when it was detected in homes the mass fractions tended to be high $\left(\mathrm{P} 90=54 \mu \mathrm{g} \mathrm{g}^{-1}, \max =860 \mu \mathrm{g} \mathrm{g}^{-1}\right)$.

It is apparent from Figure 1c that the range of mass fractions is largest for TBOEP in dust samples from daycare centers, with several extreme values exceeding $1000 \mu \mathrm{g} \mathrm{g}^{-1}$. Although the detection frequency was much smaller in homes $(28 \%$ in homes vs. $68 \%$ in daycares), when it was detected, its mass fraction was often high (P90 $=44 \mu \mathrm{g} \mathrm{g}^{-1}, \max =1$ $\left.300 \mu \mathrm{g} \mathrm{g}^{-1}\right)$. TBOEP is often used in floor polishes, acting as a leveling agent as well as a plasticizer. In homes or daycare centers where the mass fraction is high, TBOEP may be a 
constituent of the floor care product (Weschler, 1980; Marklund et al., 2003; Araki et al., 2014; Cequier et al., 2014).

For small children, dust ingestion is common and, for certain SVOCs, can be a substantial fraction of a child's total intake. Assuming a $15 \mathrm{~kg}$ child ingesting $60 \mathrm{mg}$ of dust a day (US EPA, 2009) in either indoor environment (home or daycare), daily intakes of the median mass fractions of organophosphates would be several orders of magnitude below the reference doses (RfD) presented in Van den Eede et al. (2011, and references therein). The mass fractions in dust required to exceed the RfD under such a hypothetical exposure are presented for each organophosphate in Table S1 of the Supplementary Material. The fractions of dust samples from homes with organophosphate mass fractions exceeding these limits were $0.6 \%$ for TDCIPP and $0.8 \%$ for TBOEP; in the case of daycare centers they were $4.0 \%$ for TCEP and $13 \%$ for TBOEP.

The organophosphates identified in the dust from bedrooms and daycare facilities are also anticipated to be present in the gas phase (Weschler and Nazaroff, 2010), associated with airborne particles (Weschler et al., 2008), and present on indoor surfaces. Enriched surface concentrations are specifically anticipated in the case of materials that contain organophosphates as flame retardants or plasticizers or are treated with polishes that contain such compounds. Hence, in addition to dust ingestion, intakes also occur via inhalation and dermal absorption. The latter can occur following contact with organophosphates on surfaces or, for certain compounds, directly from the gas phase (Weschler and Nazaroff, 2012; 2014). Based on estimated transdermal permeability coefficients (final column of Table 1), dermal absorption from the gas phase may only be meaningful $\left(\mathrm{k}_{\mathrm{p}-\mathrm{g}}>0.2 \mathrm{~m} \mathrm{~h}^{-1}\right)$ for TBOEP, TDCIPP, TPHP and TMPP. However, the gas phase concentrations of these low-vapor pressure compounds tend to be small, limiting the magnitude of their direct uptake from air. The overarching point is that, when inhalation intake and dermal absorption are also 
considered, the percentage of daily intakes exceeding the RfD is anticipated to be larger than those presented in the previous paragraph.

\subsection{Comparison with other studies}

To our knowledge, in terms of the number of samples (497 homes and 151 daycare centers) in combination with the number of the analyzed organophosphates (10 compounds), this is the largest study of its kind to date. A larger number of samples were collected in a few studies, but they targeted fewer organophosphates (Becker et al., 2002; Ingerowski et al., 2001).

A comparison of median mass fractions of organophosphates from this study with mass fractions previously reported in the literature is presented in Table 4. Compound by compound comparisons of our results with those reported in the literature are not appropriate, since different studies target different compounds. Hence, the following discussion is based on "when available" values from the referenced literature. Additionally, when comparing the present results with a number of earlier studies from around the world, it should be borne in mind that those studies may have relied on different sampling and analytical methods. For the purpose of direct comparison, values reported in the literature as below the limit of detection or quantification were replaced with LOD/LOQ values.

In the case of the tributyl phosphate isomers, TNBP was identified in most studies, while TIBP was identified in a few studies. Median TNBP or TIBP values exceeded $1 \mu \mathrm{g} \mathrm{g}^{-1}$ in samples from Germany (Nagorka and Ulrich, 2003), Belgium (van den Eede et al., 2011), Sweden (Bergh et al., 2011; Luongo and Östman, 2015) and Japan (Kanazawa et al., 2010; Araki et al., 2014), while the median values for the homes and daycare centers in the present study were low (for both homes and daycares 0.01 and $0.05 \mu \mathrm{g} \mathrm{g}^{-1}$ for TIBP and TNBP, 
respectively). TPHP was also found in most studies. Values for both the Danish homes and daycare centers were comparable with the Swedish (Bergh et al., 2011) and Norwegian (Cequier et al., 2014) homes and daycare centers. TPHP values $>4 \mu \mathrm{g} \mathrm{g}^{-1}$ were found in dust samples from German, U.S., Japanese, English and Swedish homes (Nagorka and Ulrich, 2003; Stapleton et al., 2009; Araki et al., 2014; Kanazawa et al., 2010; Brommer and Harrad, 2015; Luongo and Östman, 2015) and Swedish workplaces (Bergh et al., 2011). EHDPP, TEHP and TMPP were reported in approximately half of all the studies. The median values were low, and some of the median values that are seemingly elevated reflect high LODs. The chlorinated organophosphates were found in more than $2 / 3$ of the studies summarized in Table 4. In the case of TCEP, the highest mass fractions were found in the Swedish (Bergh et al., 2011) and Danish (this work) daycare centers. Comparable median concentrations were measured in homes in Japan (Araki et al., 2014; Kanazawa et al., 2010), USA (Dodson et al., 2012) and Denmark (this work), as well as in the Swedish workplaces (Berg et al., 2011). The chlorinated organophosphates are mainly used as flame retardants and commonly added to polyurethane foam (WHO, 1998). The levels of the chlorinated organophosphates in the dust samples are expected to mirror the level of fire protection mandated by law for the furniture and furnishings in the respective countries.

In Table 4 the organophosphate whose levels in indoor dust stand out is TBOEP (tris-butoxyethyl phosphate). It was found in the majority of the tabulated studies. This compound was already detected in size-selected indoor aerosols in the very early 1980s (Weschler, 1980), and is common in floor polishes (see above). Median values as high as $1600 \mu \mathrm{g} \mathrm{g}^{-1}$ were found in samples from Swedish daycare centers (Bergh et al., 2011) and in Japanese homes (Kanazawa et al., 2010). Araki et al. (2014) report median mass fractions of TBOEP of $\sim 500 \mu \mathrm{g} \mathrm{g}^{-1}$ in floor dust; houses with wooden floors had significantly higher levels of TBOEP in indoor dust, probably due to more frequent floor care. 
Figure 2 shows the sum of organophosphate mass fractions in dust from various

countries based on data from Table 4. Only entries with three or more individual organophosphates are included. The highest totals are for Swedish and Japanese homes and are due to high mass fractions of TBOEP. The sum of organophosphate levels from the Danish daycare centers was almost five times higher than the corresponding value from the Danish homes, which was comparable to most sums for other countries. The sums for daycare centers were also higher in Germany, Sweden, Norway and the UK compared to their counterparts for the homes. Subtracting TBOEP from the sums leads to a more even geographic distribution. Very low levels were found in samples from Egypt, Kuwait, New Zealand, Pakistan, the Philippines and Romania. The median mass fractions of the individual organophosphates from these countries were generally an order of magnitude lower than from the other countries. In general, the mass fraction of organophosphate esters in dust displayed greater country-to-country variation than observed for the mass fraction of phthalate esters in dust (Langer et al., 2010), reflecting less extensive global use of the organophosphates.

\section{Summary}

The mass fractions of organophosphates in dust were higher in samples from daycare centres than in samples from homes. The targeted compounds were present at levels below the limit of detection in the majority of the dust samples. Median mass fractions above the $1 / 2$ the limit of detection were measured for TCEP from the home samples and TCEP, TCIPP, TDCIPP, TBOEP, TPHP and EHDPP from the daycare center samples. Although TBOEP was not the most frequently detected of the ten targeted organophosphates, its median mass fraction was the highest of all the organophosphates. The values measured in this study were in line with values reported for other industrialized countries. 

more or less evenly distributed over the globe (Langer et al., 2010). For the children targeted in this study, based on mass fractions found in dust from their homes and daycare centers, intake of organophosphates through dust ingestion was in most instances below current guidelines. However, inhalation and dermal absorption are also anticipated to be substantial exposure pathways for organophosphates in indoor environments.

\section{Acknowledgement}

We would like to thank the VILLUM FOUNDATION for generous support of this study and the participating families for their cooperation. We would also like to acknowledge Andreas Fischer for the analytical work with the samples.

\section{References}

Abdallah, M.A.-E., Covaci, A., 2014. Organophosphate flame retardants in indoor dust from Egypt: Implications for human exposure. Environ. Sci. Technol. 48, 4782-4789. Ali, N., Dirtu, A.C., Van den Eede, N., Goosey, E., Harrad, S., Neels, H., Mannetje, A., Coakley, J., Douwes, J., Covaci A., 2012a. Occurrence of alternative flame retardants in indoor dust from New Zealand: Indoor sources and human exposure assessment. Chemosphere 88, 1276-1282.

Ali, N., Van den Eede N., Dirtu A.C., Neels H., Covaci A., 2012b. Assessment of human exposure to indoor organic contaminants via dust ingestion in Pakistan. Indoor Air 22, 200211. and profiles of organochlorines and flame retardants in car and house dust from Kuwait and Pakistan: Implication for human exposure via dust ingestion. Environ.Int. 55, 62-70. plasticisers in surface waters. Sci. Total Environ. 332, 155-166. 
Araki, A., Saito, I., Kazanawa, A., Morimoto, K., Nakayama, K., Shibata, E., Tanaka, M., Takigawa, T., Yoshimura, T., Chikara, H., Saiko, Y., Kishi R., 2014. Phosphorus flame retardants in indoor dust and their relation to asthma and allergies of inhabitants. Indoor Air 24, 3-15.

Becker, K., Seiwert, M., Kaus, S., Krause, C., Schults, C., Seifert B., 2002. German Environmental Survey (GerES III): Pesticides and other pollutants in indoor dust. Proceedings Indoor Air 2002, 883-886.

Bergh, C., Torgrip, R., Emenius, G., Östman, C., 2011. Organophosphate and phthalate esters in air and settled dust - a multi-location indoor study. Indoor Air 21, 67-76.

Bergman, Å., Rydén, A., Law, R.J., de Boer, J., Covaci, A., Alaee, M., Birnbaum, L., Petreas, M., Rose, M., Sakai, S., Van den Eede, N., van der Veen, I., 2012. A novel abbreviation standard for organobromine, organochlorine and organophosphorus flame retardants and some characteristics of the chemicals. Environ. Int. 49, 57-82.

Brommer, S., Harrad, S., Van den Eede, N., Covaci, A., 2012. Concentrations of organophosphate esters and brominated flame retardants in German indoor dust samples. J. Environ. Monit. 14, 2482-2487.

Brommer, S., Harrad, S., 2015. Sources and human exposure implications of concentrations of organophosphate flame retardants in dust from UK cars, classrooms, livin roms, and offices. Environ.Int. 83, 202-207.

Cequier, E., Ionas, A.C., Covaci, A., Marcé, R.M., Becher, G., Thomsen, C., 2014. Occurence of a broad range of legecy and emerging flame retardants in indoor environments in Norway. Environ.Sci. Technol. 48, 6827-6835.

Cequier, E., Sakhi A.K., Marcé, R.M., Becher, G., Thomsen, K., 2015. Human exposure pathways to organophosphate triesters - A biomonitoirng study of mother-child pairs. Environ. Int. 75, 159-165.Clausen, G., Høst, A., Toftum, J., Bekö, G., Weschler, C., Callesen, M., Buhl, S., Ladegaard, M., Langer, S., Andersen, B., Sundell, J., Bornehag, C.G., Sigsgaard, T., 2012. Children's health and its association with indoor environments in Danish homes and daycare centres - methods. Indoor Air 22, 467-475.

Dirtu, A.C., Ali, N, van den Eede, N., Neels, H., Covaci, A., 2012. Country specific comparison for profile of chlorinated, brominated and phosphate organic contaminants in indoor dust. Case study for eastern Romania. Environ. Int. 49, 1-8.

Dodson, R.E., Perowich, L.J., Covaci, A., van den Eede, N., Ionas, A.C., Dirtu, A.C., Brody, J.G., Rudel ,R.A., 2012. After the PBDE phase-out: a broad suite of flame retardants in repeat house dust samples from California. Environ. Sci. Technol. 46, 13056-13066.

Fan, X., Kubwabo C., Rasmussen, P.E., Wu F., 2014. Simultaneous determination of thirteen organophosphate esters in settled indoor house dust and comparison between two sampling techniques. Sci. Total Environ. 491-492, 80-86. 
412 Fromme, H., Lahrz, T., Kraft ,M., Fembacher, L., Mach, C., Dietrich, S., Burkardt, R.,

413 Völkel, W., Göen, T., 2014. Organophosphate flram retardants and plasticizers in the air and

414 dust in German daycare centers and human biomonitoring in visiting children (LUOE 3).

415 Environ.Int. 71, 158-163.

416 García, M., I. Rodríguez, Cela R., 2007. Microwave-assisted extraction of organophosphate

417 flame retardants and plasticizers from indoor dust samples. J. Chromatography A, 1152, 280418286.

419 Hansen, D., Voland, G., Krause, G., Zöltze,r D., 2001. Determination and occurrence of 420 phosphororganic compounds (POV) in dust and indoor air. Gefahrstoffe - Reinhaltung der 421 luft 61, 13-17 (in German).

422 He, C.-T., Zheng, J., Qiao, L., Chen, S.-J., Yang, J.-Z., Yuan, J.-C., Yang, Z.-Y., Mai, B.-X., 423 2015. Occurance of organophosphorus flame retardants in indoor dust in multiple 424 environments of southern China and implications for human exposure. Chemosphere 133, 4742552.

426 Hoffman, K., Daniels, J.L., Stapleton, H.M., 2014. Urinary metabolites of organophosphate 427 flame retardants and their variability in pregnant women. Environ. Int. 63, 169-172.

428 Hoffman, K., Garantziotis, S., Birnbaum, L.S., Stapleton, H., 2015. Monitoring indoor 429 exposure to organophosphate flame retardants: Hand wipes and house dust. Environ. Health 430 Perspect. 123, 160-165.

431 Ingerowski, G., Friedle, A., Thummulla, J., 2001. Chlorinated ethyl and isopropyl phosphoric 432 acid triesters in the indoor environment - an interlaboratory exposure styudy. Indoor Air 11, $433 \quad 145-149$.

434 Kazanawa, A., Saito, I., Araki, A., Takeda, M., Ma, M., Saijo, Y., Kishi R., 2010. Association 435 between indoor exposure to semi-volatile organic compounds and building-related symptoms 436 among the occupants of residential dwellings. Indoor Air 20, 72-84.

437 Kersten, W., Reich, T., 2003. Non-volatile organic substances in Hamburg indoor dust. 438 Gefahrstoffe Reinhaltung der Luft 63, 85-91 (in German).

439 Kim, J.-W., Isobe, T., Sudaryanto, A., Malarvannan, G., Chang, K.-H., Muto, M., Prudente, 440 M., Tanabe, S., 2013. Organophosphorus flame retardants in house dust from the Philippines: 441 occurrence and assessment of human exposure. Environ. Sci. Poll. Res. 20, 812-822.

442 Langer, S., Weschler, C.J., Fischer, A., Bekö, G., Toftum, J., Clausen, G., 2010. Phthalate 443 and PAH concentrations in dust collected from Danish homes and daycare centers. Atmos. 444 Environ. 44, 2294-2301.

445 Luongo, G., Östman, C., 2015. Organophosphate and phthalate esters in settled dust from 446 apartment building in Stockholm. Indoor Air, DOI: 10.1111/ina.12217. 
Marklund, A., Andersson, B., Haglund, P., 2003. Screening of organophosphorus compounds and their distribution in various indoor environments. Chemosphere 53, 1137-1146.

Marklund, A., Andersson, B., Haglund, P., 2005. Organophosphorus flame retardants and plasticizers in air from various indoor environments. J. Environ. Monit. 7, 814-819.

Meeker, J.D., Stapleton, H.M., 2010. House dust concentration of organophosphate flame retardants in relation to hormone levels and semen quality parameters. Environ. Health Perspect. 118, 318-323.

Nagorka, R., Ullrich, D., 2003. Determination of organophosphorus flame retardants in indoor dust: Screening method with GC/NPD. Gefahrstoffe Reinhaltung der Luft 63, 79-84. (in German).

Ott, W. R., 1995. Environmental Statistics and Data Analysis. Ann Arbor, Lewis Publishers.

Reemtsma, T., Lingott, J., Roegler, S., 2011. Determination of 14 monoalkyl phosphates, dialkyl phosphates and dialkyl thiophosphates by LC-MS/MS in human urinary samples. Sci. Total Environ. 409, 1990-1993.

Rudel, R.A., Camann, D.E., Spengler, J.D., Korn, L.R., Brody, J.G., 2003. Phthalates, alkylphenols, pesticides, polybrominated diphenyl ethers, and other endocrine-disrupting compounds in indoor air and dust. Environ. Sci. Technol. 37, 4543-4553.

Sagunski, H., Ingerowski, G., Mattulat, A., Scheutvinkel ,M., 1997. Exposure and environmental health evaluation of tris(2-chloroethyl)phosphate. Umweltmedizin in Forschung und Praxis 2, 185-192 (in German).

Shields, H.C., Fleischer, D.M., Weschler, C.J., 1996. Comparisons among VOCs measured in three types of US commercial buildings with different occupant densities. Indoor Air 6, 2-17.

Shin, H.M., McKone, T.E., Tulve, N.S., Clifton, M.S., Bennett, D.H., 2013. Indoor residence times of semivolatile organic compounds: Model estimation and field evaluation. Environ. Sci. Technol.47, 859-867.

Shin, H.M., McKone, T.E., Nishioka, M.G., Fallin, M.D., Croen, L.A., Hertz-Picciotto, I., Newschaffer, C.J., Bennett, D.H., 2014. Determining source strength of semivolatile organic compounds using measured concentrations in indoor dust. Indoor Air 24, 206-271.

Staaf, T., Östman, C., 2005. Organophosphate triesters in indoor environments. J. Environ. Monit. 7, 883-887.

Stapleton, H.M., Klosterhaus, S., Eagle, S., Fuh, J., Meeker, J.D., Blum, A., Webster, T.F., 2009. Detection of Organophosphate Flame Retardants in Furniture Foam and U.S. House Dust. Environ. Sci.Technol. 43,7490-7495.

Tajima, S., Araki, A., Kawai, T., Tsuboi ,T., Bamai, Y.A., Yoshioka, E., Kanazawa, A., Cong, S., Kiski, R., 2014. Detection and intake assessment of organophosphate flame retardants in house dust in Japanese dwellings. Sci. Total Environ. 478, 190-199. 
Taylor, J., 1987. Quality assurance of chemical measurements. Lewis Publishers. p. 79-81. ISBN 0-87371-097-5.

Toda, H., Sako, K., Yagome, Y., Nakamura, T., 2004. Simultaneous determination of phosphate esters and phthalate esters in clean room air and indoor air by gas chromatographymass spectrometry. Anal. Chim. Acta 519, 213-218.

US EPA, 2009. Highlights of the Child-specific exposure factors handbook (Final Report). US Environmental Protection Agency, Washington, DC, EPA/600/R-08/135, Available: http://cfpub.epa.gov/ncea/risk/recordisplay.cfm?deid=200445\&CFID=55467099\&CFTOKEN $=81128915$. Accessed 2016 January 13.

Van den Eede N., Dirtu A.C., Neels H., Covaci A., 2011. Analytical developments and preliminary assessment of human exposure to organophosphate flame retardants from indoor dust. Environ. Int. 37, 454-461.

Wensing, M., Uhde, E., Salthammer, T., 2005. Plastics additives in the indoor environment flame retardants and plasticizers. Sci. Total Environ. 339, 19-40.

Weschler, C.J., 1980. Characterization of selected organics in size-fractionated indoor aerosols. Environ. Sci. Technol. 14, 428-431.

Weschler, C.J., 1984. Indoor-outdoor relationships for nonpolar organic constituents of aerosol particles. Environ. Sci.Technol. 18, 648-652.

Weschler, C.J., Nazaroff, W.W., 2008. Semivolatile organic compounds in indoor environments. Atmos. Environ. 42, 9018-9040.

Weschler, C.J., Salthammer, T., Fromme, H., 2008. Partitioning of phthalates among the gas phase, airborne particles and settled dust in indoor environments. Atmos. Environ. 42, 14491460 .

Weschler, C.J., Nazaroff, W.W., 2010. SVOC partitioning between the gas phase and settled dust indoors. Atmos. Environ. 44, 3609-3620.

Weschler, C.J., Langer, S., Fischer, A., Bekö, G., Toftum, J., Clausen, G., 2011. Squalene and cholesterol in dust from Danish homes and daycare centers. Environ. Sci.Technol. 45, 38723879 .

Weschler, C.J., Nazaroff, W.W. 2012. SVOC exposure indoors: fresh look at dermal pathways. Indoor Air 22, 356-377.

Weschler, C.J., Nazaroff, W.W., 2014. Dermal uptake of organic vapors commonly found in indoor air. Environ. Sci.Technol 48, 1230-1237.

WHO (1991a). Tri-n-butyl Phosphate, Environmental Health Criteria 112, World Health Organization, Geneva.

WHO (1991b). Triphenyl Phosphate, Environmental Health Criteria 111, World Health Organization, Geneva. 
519 WHO (1998). Flame retardants: Tris(chloropropyl) Phosphate and Tris(2-chloroethyl)

520 Phosphate, Environmental Health Criteria 209, World Health Organization, Geneva.

521 WHO (2000). Flame retardants: Tris(2-butoxyethyl) Phosphate and Tris(2-ethylhexyll)

522 Phosphate and Tetrakis(hydroxymethyl) Phosphonium salts, Environmental Health Criteria 523 218, World Health Organization, Geneva. 
Table 1. Names, abbreviations, CAS numbers, molecular weight (MW), the $\mathrm{m} / \mathrm{z}$ of the most abundant ion and transdermal permeability coefficients $\mathrm{k}_{\mathrm{p}-\mathrm{g}}\left(\mathrm{m} \mathrm{h}^{-1}\right)$ of the organophosphates investigated in this work.

\begin{tabular}{|l|l|r|r|r|r|}
\hline Chemical name & Abbrevation* & CAS \# & MW & $\mathbf{~ m / z}$ & $\begin{array}{c}\mathbf{k}_{\mathbf{p - g}} \mathbf{* *} \\
\left(\mathbf{m ~ h}^{\mathbf{- 1}} \mathbf{)}\right.\end{array}$ \\
\hline \hline Tris(isobutyl) phosphate & TIBP & $126-71-6$ & 266 & 99 & 0.0002 \\
\hline Tri-n-butyl phosphate & TNBP & $126-73-8$ & 266 & 99 & 0.002 \\
\hline Tris(2-chloroethyl) phosphate & TCEP & $115-96-8$ & 285 & 63 & 0.039 \\
\hline Tris(2-chloroisopropyl) phosphate & TCIPP & $13674-84-5$ & 327 & 125 & 0.011 \\
\hline Tris(1,3-dichloroisopropyl) phosphate & TDCIPP & $13674-87-8$ & 431 & 75 & 1.3 \\
\hline Tris(2-butoxyethyl) phosphate & TBOEP & $78-51-3$ & 398 & 57 & 5.3 \\
\hline Tri-phenyl phosphate & TPHP & $115-86-6$ & 326 & 326 & 0.68 \\
\hline 2-Ethylhexyl-diphenyl phosphate & EHDPP & $1241-94-7$ & 362 & 251 & 0.046 \\
\hline Tris(2-etylhexyl) phosphate & TEHP & $78-42-2$ & 434 & 99 & 0.002 \\
\hline Tris(methylphenyl) phosphate & TMPP & $78-32-0$ & 368 & 368 & 0.69 \\
\hline
\end{tabular}

*The compounds are abbreviated according to the nomenclature presented by Bergman et al. (2012).

**Calculated using the procedure outlined in Weschler and Nazaroff (2012).

Table 2. Mass fractions $\left(\mu \mathrm{g} \mathrm{g}^{-1}\right)$ of the organophosphates found in settled dust from homes $(\mathrm{n}=497)$ and daycare centers $(\mathrm{n}=151)$. Values in each cell are listed as "homes/daycare centers". Detection frequency (DF) is percentage of samples found in concentrations above the detection limit (LOD). LOD values are the same for both homes and daycare centers. Median mass fractions and P90, respectively, above the LOD are reported in the table.

\begin{tabular}{|l|c|c|c|c|c|}
\hline Compound & DF $(\%)$ & LOD & Median & P90 & Max. \\
\hline \hline TIBP & $31 / 30$ & 0.027 & $* / *$ & $0.95 / 0.37$ & $37 / 2.5$ \\
\hline TNBP & $22 / 14$ & 0.11 & $* / *$ & $0.26 / 0.13$ & $4.0 / 4.3$ \\
\hline TCEP & $69 / 78$ & 0.60 & $6.9 / 16$ & $42 / 230$ & $230 / 1800$ \\
\hline TCIPP & $37 / 72$ & 1.1 & $* / 5.6$ & $6.1 / 41$ & $100 / 350$ \\
\hline TDCIPP & $41 / 67$ & 1.2 & $* / 7.1$ & $54 / 69$ & $860 / 320$ \\
\hline TBOEP & $28 / 68$ & 0.40 & $* / 26$ & $44 / 420$ & $1300 / 11000$ \\
\hline TPHP & $21 / 65$ & 0.94 & $* / 2.0$ & $1.8 / 16$ & $91 / 210$ \\
\hline EHDPP & $29 / 77$ & 0.14 & $* / 2.1$ & $1.2 / 28$ & $11 / 540$ \\
\hline TEHP & $0.80 / 1.3$ & 2.5 & $* / *$ & $* / *$ & $11 / 3.8$ \\
\hline TMPP & $1.6 / 1.6$ & 0.89 & $* / *$ & $* / *$ & $18 / 36$ \\
\hline
\end{tabular}


Table 3. Spearman correlation coefficients for the individual organophosphates.

\begin{tabular}{|c|c|c|c|c|c|c|c|c|c|c|}
\hline Homes & TIBP & TNBP & TCEP & TCIPP & TDCIPP & TBOEP & ТPHP & EHDPP & TEHP & TMPP \\
\hline TIBP & 1 & & & & & & & & & \\
\hline TNBP & $0.400^{*}$ & 1 & & & & & & & & \\
\hline TCEP & $0.572 *$ & $0.408^{*}$ & 1 & & & & & & & \\
\hline TCIPP & $0.333^{*}$ & $0.375^{*}$ & $0.395^{*}$ & 1 & & & & & & \\
\hline TDCIPP & $0.192^{*}$ & $0.175^{*}$ & $0.376^{*}$ & $0.119^{*}$ & 1 & & & & & \\
\hline TBOEP & $0.283^{*}$ & $0.145^{*}$ & $0.316^{*}$ & $0.248^{*}$ & $0.154^{*}$ & 1 & & & & \\
\hline ТPHP & $0.314^{*}$ & $0.214^{*}$ & $0.366^{*}$ & $0.251 *$ & $0.098^{*}$ & $0.217^{*}$ & 1 & & & \\
\hline EHDPP & $0.260^{*}$ & $0.242 *$ & $0.315^{*}$ & $0.351^{*}$ & 0.084 & $0.312^{*}$ & $0.422^{*}$ & 1 & & \\
\hline TEHP & -0.002 & $0.105^{*}$ & $0.089^{*}$ & 0.020 & 0.049 & 0.046 & 0.018 & 0.073 & 1 & \\
\hline TMPP & 0.048 & -0.010 & 0.026 & 0.032 & 0.014 & $0.094 *$ & $0.104^{*}$ & $0.106^{*}$ & -0.018 & 1 \\
\hline Daycare centers & TIBP & TNBP & TCEP & TCIPP & TDCIPP & TBOEP & ТPHP & EHDPP & TEHP & TMPP \\
\hline TIBP & 1 & & & & & & & & & \\
\hline TNBP & $0.491^{*}$ & 1 & & & & & & & & \\
\hline TCEP & $0.378^{*}$ & $0.253^{*}$ & 1 & & & & & & & \\
\hline TCIPP & $0.436^{*}$ & $0.302 *$ & $0.478^{*}$ & 1 & & & & & & \\
\hline TDCIPP & $0.406^{*}$ & $0.204 *$ & $0.367^{*}$ & $0.593 *$ & 1 & & & & & \\
\hline TBOEP & $0.281^{*}$ & 0.104 & $0.261^{*}$ & $0.282^{*}$ & $0.233^{*}$ & 1 & & & & \\
\hline TPHP & $0.219^{*}$ & $0.190 *$ & $0.313^{*}$ & $0.492 *$ & $0.407 *$ & $0.209^{*}$ & 1 & & & \\
\hline EHDPP & $0.184 *$ & $0.193^{*}$ & $0.265^{*}$ & $0.438^{*}$ & $0.264 *$ & $0.178^{*}$ & $0.597 *$ & 1 & & \\
\hline TEHP & 0.041 & 0.079 & -0.009 & 0.020 & -0.066 & 0.027 & 0.085 & 0.083 & 1 & \\
\hline TMPP & $0.222 *$ & 0.129 & 0.117 & $0.175^{*}$ & 0.071 & 0.039 & $0.231^{*}$ & 0.108 & -0.019 & 1 \\
\hline
\end{tabular}

$* \mathrm{p}<0.05$ 
Table 4. Organophosphate mass fractions $\left(\mu \mathrm{g} \mathrm{g}^{-1}\right)$ in dust samples collected from residences and other indoor spaces as reported in relevant studies. Present results listed for comparison; the values in bold are organophosphates in this study with the median above LOD. All values are medians unless stated otherwise.

\begin{tabular}{|c|c|c|c|c|c|c|c|c|c|c|c|c|c|}
\hline Reference & Country & Location & $\mathbf{n}$ & TIBP & TNBP & TCEP & TCIPP & TDCIPP & TBOEP & TPHP & EHDPP & TEHP & TMPP \\
\hline Sagunski et al. (1997) & Germany & Homes & 59 & --- & --- & 0.9 & --- & --- & --- & --- & --- & -- & -- \\
\hline Ingerowski et al. (2001) & Germany & Homes & 983 & --- & --- & 0.66 & --- & --- & --- & --- & --- & --- & --- \\
\hline Ingerowski et al. (2001) & Germany & Homes & 436 & --- & --- & --- & 0.57 & --- & --- & --- & --- & --- & --- \\
\hline Becker et al. (2002) & Germany & Homes & 199 & --- & --- & $<0.1$ & --- & --- & 5.8 & 0.3 & --- & $<0.1$ & $<0.1$ \\
\hline Kersten and Reich (2003) & Germany & Homes & 65 & --- & 0.4 & 1.6 & 1.4 & 1.2 & 5 & 2.9 & --- & 0.2 & 2.2 \\
\hline Marklund et al. (2003) & Sweden & Various indoor spaces & 15 & --- & 0.35 & 1.4 & 2.4 & 1.1 & 31 & 3.1 & --- & 0.16 & --- \\
\hline Nagorka and Ulrich (2003) & Germany & Homes & 28 & --- & 2.5 & 2.5 & --- & 1.7 & 16.1 & 6.5 & 0.8 & 0.8 & --- \\
\hline García et al. (2007) & Spain & Homes & 8 & 0.22 & 0.23 & 0.51 & 3.8 & --- & 9.4 & 1.9 & --- & --- & --- \\
\hline Stapleton et al. (2009) & USA & Homes & 50 & --- & --- & --- & 0.57 & 1.9 & --- & 7.4 & --- & --- & --- \\
\hline Kanazawa et al. (2010) & Japan & Homes & 41 & -- & 1.4 & 7.5 & 18.7 & 4 & 1570 & 5.4 & -- & 4.3 & --- \\
\hline Meeker and Stapleton (2010) & USA & Homes & 50 & --- & --- & --- & --- & 1.8 & --- & 5.5 & --- & --- & --- \\
\hline Van den Eede et al. (2011) & Belgium & Homes & 33 & 3.0 & 0.13 & 0.23 & 1.4 & 0.36 & 2.0 & 0.50 & --- & --- & 0.20 \\
\hline Van den Eede et al. (2011) & Belgium & Shops & 15 & 1.0 & 0.21 & 0.59 & 2.9 & 0.76 & 3.6 & 2.0 & --- & --- & 0.02 \\
\hline Bergh et al. (2011) & Sweden & Home & 10 & 1.1 & 0.3 & 2.1 & 1.6 & 10 & 4 & 1.2 & 0.5 & n.d. & -- \\
\hline Bergh et al. (2011) & Sweden & Day-care centers & 10 & 0.7 & 1.2 & 30 & 3.1 & 9.1 & 1600 & 1.9 & 0.8 & 0.1 & --- \\
\hline Bergh et al. (2011) & Sweden & Work & 10 & 1.3 & 0.2 & 6.7 & 19 & 17 & 87 & 5.3 & 1.0 & n.d. & --- \\
\hline Ali et al. (2012a) & New Zealand & Homes (Floor dust) & 34 & --- & 0.08 & 0.11 & 0.35 & --- & 4.02 & 0.6 & --- & --- & 0.1 \\
\hline Ali et al. (2012a) & New Zealand & Homes (Mattrasses) & 16 & --- & 0.07 & 0.04 & 0.25 & --- & 1.55 & 0.24 & --- & --- & 0.2 \\
\hline Ali et al. (2012b) & Pakistan & Homes & 31 & --- & 0.014 & --- & --- & 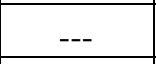 & 0.027 & 0.094 & 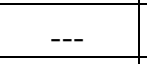 & --- & --- \\
\hline Brommer et al. (2012)* & Germany & Homes & 6 & --- & 0.13 & 0.20 & 0.74 & $<0.080$ & 0.73 & 0.38 & -- & -- & 0.1 \\
\hline Brommer et al. (2012)* & Germany & Offices & 10 & --- & 0.22 & 0.12 & 3.0 & 0.15 & 7.0 & 2.5 & --- & --- & 0.4 \\
\hline Dirtu et al. (2012) & Romania & Homes & 47 & 0.39 & 0.045 & 0.10 & 0.86 & 0.06 & 1.5 & 0.50 & --- & --- & 0.50 \\
\hline Dodson et al. (2012) & USA 2006 & Homes & 16 & 0.084 & 0.032 & 5.1 & 2.1 & 2.8 & 12 & --- & 0.61 & $<0.2$ & 1 \\
\hline Dodson et al. (2012) & USA 2011 & Homes & 16 & $<0.080$ & $<0.080$ & 2.7 & 2.2 & 2.1 & 11 & --- & 0.56 & $<0.2$ & 0.68 \\
\hline
\end{tabular}




\begin{tabular}{|c|c|c|c|c|c|c|c|c|c|c|c|c|c|}
\hline Ali et al. (2013) & Kuwait & Homes & 15 & 0.054 & 0.058 & 0.71 & 1.46 & 0.36 & 0.86 & 0.43 & 0.19 & 0.065 & 0.16 \\
\hline Ali et al. (2013) & Pakistan & Homes & 15 & 0.025 & $<0.020$ & 0.015 & $<0.020$ & $<0.005$ & 0.017 & 0.175 & 0.067 & 0.02 & 0 \\
\hline Kim et al. (2013) & Philippines & Homes (Malate) & 37 & --- & 0.019 & 0.034 & --- & --- & --- & 0.089 & 0.11 & 0.14 & 0 \\
\hline Kim et al. (2013) & Philippines & Homes (Payatas) & 20 & --- & 0.020 & 0.016 & --- & --- & --- & 0.074 & 0.034 & 0.041 & 0 \\
\hline Araki et al. (2014) & Japan & Homes (Floor) & 148 & --- & 1.0 & 5.8 & 8.7 & 2.8 & 508 & 4.5 & --- & 2.1 & $<4.0$ \\
\hline Araki et al. (2014) & Japan & Homes (Multi-surface) & 120 & --- & 1.2 & 8.3 & 25.8 & 10.8 & 111 & 11.5 & --- & 1.5 & $<4.0$ \\
\hline Tajima et al. (2014) & Japan & Homes (Floor) & 48 & --- & $<0.36$ & $<0.65$ & 0.74 & $<0.59$ & 31 & 0.9 & --- & $<0.67$ & $<4.0$ \\
\hline Tajima et al. (2014) & Japan & Homes (Upper surfaces) & 128 & --- & 0.74 & 1.17 & 2.23 & $<0.59$ & 26.55 & 3.13 & --- & $<0.67$ & $<4.0$ \\
\hline Abdallah and Covaci (2014) & Egypt & Homes & 20 & 0.023 & 0.017 & 0.022 & 0.028 & 0.072 & 0.018 & 0.067 & 0.042 & --- & -- \\
\hline Abdallah and Covaci (2014) & Egypt & Offices & 20 & 0.028 & 0.023 & 0.031 & 0.080 & 0.049 & 0.143 & 0.073 & 0.048 & --- & --- \\
\hline Cequier et al. (2014) & Norway & Homes & 48 & --- & 0.06 & 0.41 & 2.68 & 0.50 & 13.4 & 0.98 & 0.62 & --- & 0.31 \\
\hline Cequier et al. (2014) & Norway & Classrooms & 6 & --- & 0.04 & 1.21 & 2.04 & 1.49 & 87.2 & 1.54 & 2.34 & --- & 0.06 \\
\hline Fan et al., 2014 & Canada & Homes (fresh dust) & 134 & & 0.25 & 0.80 & 1.4 & 2.7 & 31.9 & 1.70 & 0.54 & --- & 2.60 \\
\hline Fromme et al., 2014 & Germany & Day-care centers & 63 & $<0.30$ & $<0.30$ & 0.40 & 2.68 & --- & 225 & 0.50 & 1.10 & 0.50 & --- \\
\hline Shin et al., 2014 & USA & Homes & 30 & --- & --- & 0.50 & --- & 3.6 & --- & 2.0 & --- & --- & --- \\
\hline Brommer \& Harrad, 2015 & UK & Homes (living rooms) & 32 & --- & $<0.03$ & 0.81 & 21 & 0.71 & --- & 3.3 & 1.6 & --- & 0 \\
\hline Brommer \& Harrad, 2015 & UK & Offices & 61 & --- & $<0.03$ & 0.87 & 33 & 0.48 & --- & 4.3 & 5.3 & --- & $<0.01$ \\
\hline Brommer \& Harrad, 2015 & UK & Schools, day-care centers & 28 & --- & 0.12 & 0.86 & 16 & 0.51 & --- & 4.1 & 29 & --- & $<0.01$ \\
\hline He et al., 2015 & China & Rural homes & 25 & --- & 0.14 & 1.93 & 1.22 & 0.15 & 0.20 & 1.09 & 0.31 & 0.19 & --- \\
\hline He et al., 2015 & China & Urban homes & 11 & --- & 0.08 & 3.78 & 0.75 & 0.13 & 0.32 & 0.15 & 0.36 & 0.14 & -- \\
\hline Hoffman et al., 2015 & USA & Homes & 49 & --- & --- & --- & --- & 1.39 & --- & 1.02 & --- & --- & --- \\
\hline Luongo and Östman, 2015 & Sweden & Homes & 62 & 5.3 & 5.6 & 4.0 & 11 & 2.0 & 11 & 4.3 & 2.7 & --- & 2.7 \\
\hline This work & Denmark & Homes & 497 & 0.03 & 0.1 & 6.9 & 1.1 & 1.2 & 0.4 & 0.9 & 0.1 & 2.5 & 0.9 \\
\hline This work & Denmark & Day-care centers & 151 & 0.03 & 0.1 & 16.2 & 5.6 & 7.1 & 26.2 & 2.0 & 2.1 & 2.5 & 0.9 \\
\hline
\end{tabular}

n.d. not detected; --- not available/investigated; * mean values. 
Figure 1.
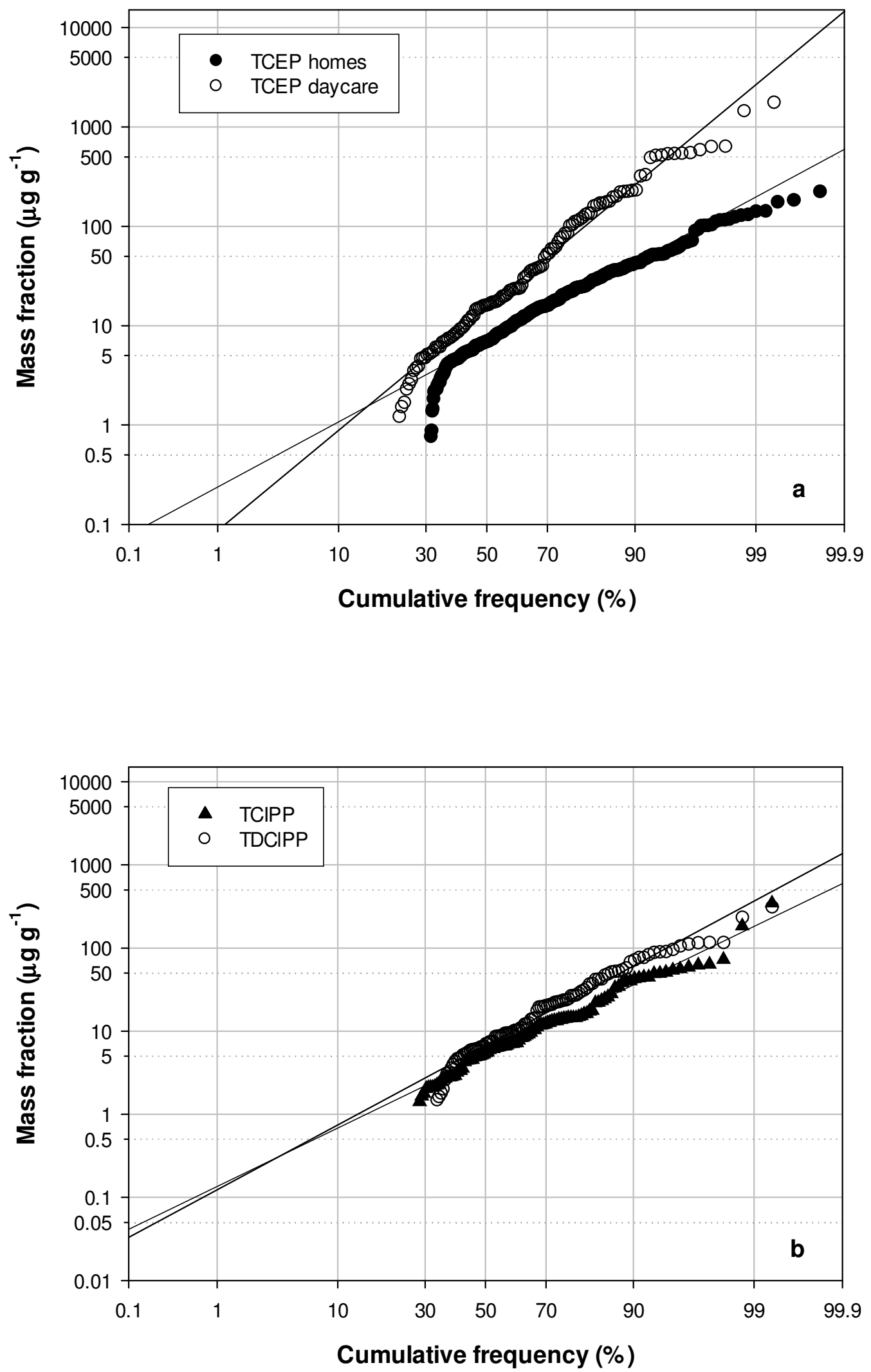


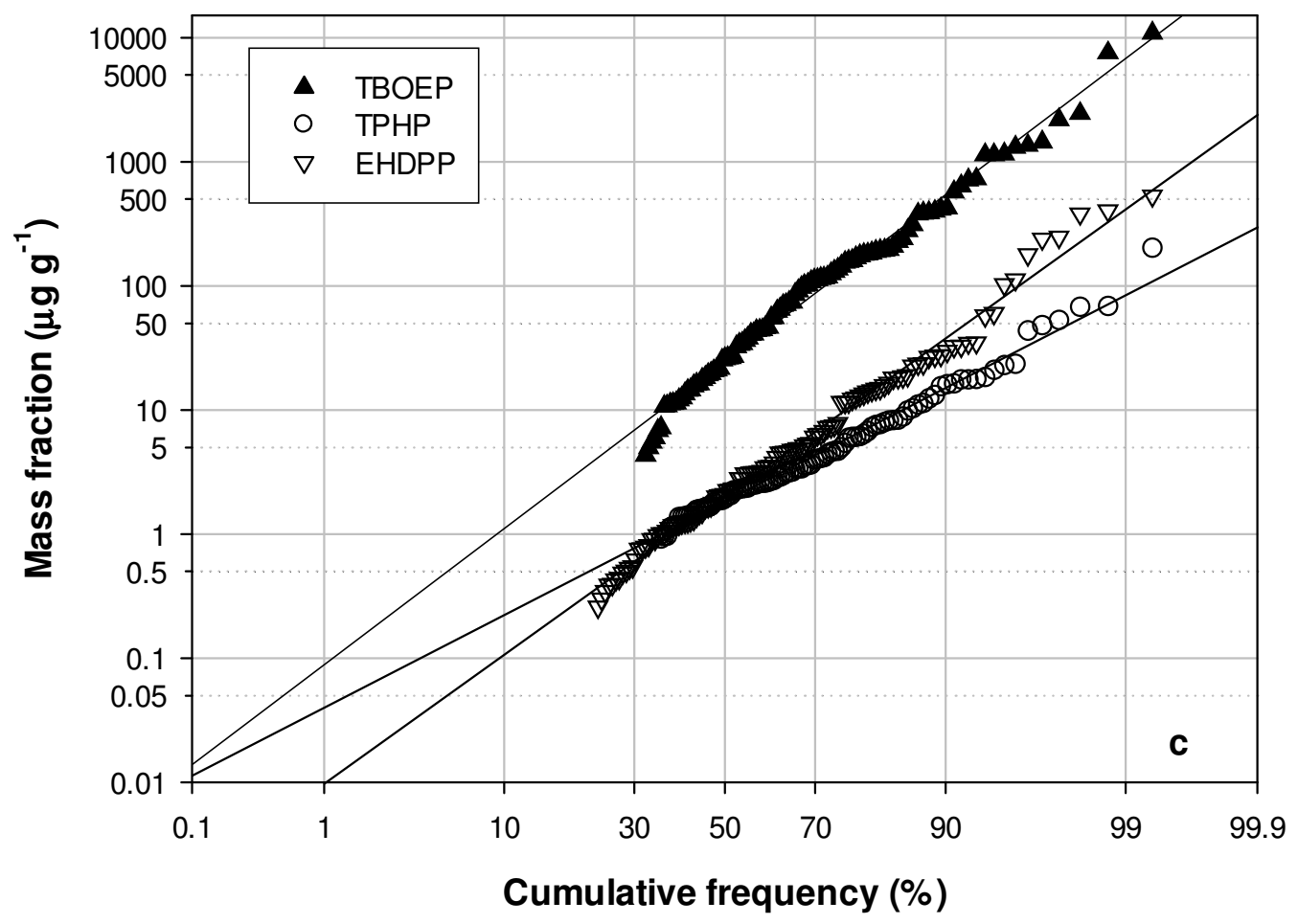


Figure 2.

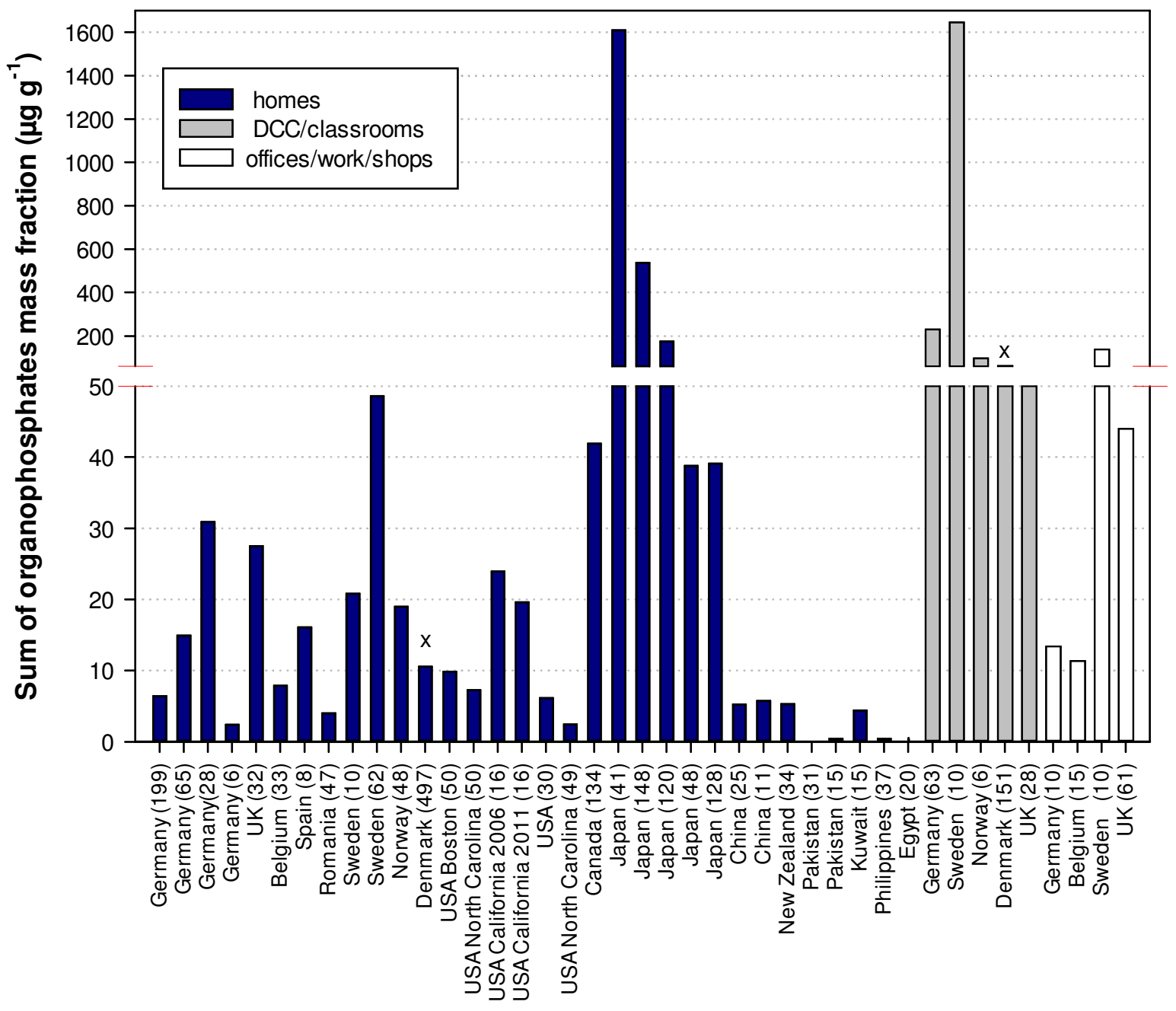




\section{Figure Captions}

Figure 1. Cumulative frequency distributions of measured mass fractions of a) TCEP in dust from homes (filled circle) and daycare centers (open circles); b) TCIPP (filled triangles) and TDCIPP (open circles) in dust from daycare centers; c) TBOEP (filled triangles), TPHP (open circles) and EHDPP (open triangles) in dust from daycare centers.

Figure 2. Geographic distribution of the sum of organophosphates reported in indoor dust from homes, daycare centers (DCC), classrooms (school) and various work environments (offices, shops, work). The data are selected from Table S1; entries with two or more individual organophosphates are included. The references can be identified by mapping country and number of samples with corresponding information in Table 4. Results from this work are marked with an " $x$ ". 